\title{
Time-varying long range dependence in market returns of FEAS members ${ }^{\text {is }}$
}

\author{
A. Sensoy* \\ Borsa Istanbul, Research Department, Resitpasa Mahallesi, Tuncay Artun Caddesi, Emirgan, Istanbul 34467, Turkey \\ Bilkent University, Department of Mathematics, Ankara 06800, Turkey
}

\section{A R T I C L E I N F O}

\section{Article history:}

Received 23 January 2013

Accepted 7 May 2013

Available online 3 June 2013

\begin{abstract}
A B S T R A C T
We study the time-varying efficiency of nineteen members of the Federation of Euro-Asian Stock Exchanges (FEAS - an international organization comprising the main stock exchanges in Eastern Europe, the Middle East and Central Asia) by generalized Hurst exponent analysis of daily data with a rolling window technique. The study covers the six years of time period between January 2007 and December 2012. The results reveal that all FEAS members exhibit different degrees of long range dependence varying over time. We present an efficiency ranking of these members that provides guidance for investors and portfolio managers. Results show that the least inefficient market is Turkey followed by Romania while the most inefficient markets are Iran, Mongolia, Serbia and Macedonia. Throughout the considered time period, Turkey's stable Hurst exponent around 0.5 differs from others and shows characteristics of a developed financial market. For the federation members, strong positive relationship between efficiency and market liquidity is revealed. In the light of this fact, alternatives are suggested to improve market efficiency.
\end{abstract}

(c) 2013 Elsevier Ltd. All rights reserved.

\section{Introduction}

Market efficiency simply states that the price in the stock market reflects all the available information. According to highly controversial efficient market hypothesis $(\mathrm{EMH})$ of Fama [1], when all the information about the investments is known, it is not possible for anyone to beat the market and expect returns that are above average. EMH views market prices as random thus serial correlations between observations cannot exist. While short term serial correlation is accepted by supporters of EMH, long term serial correlation is generally rejected.

The long memory in asset returns has been an intriguing subject for a long time. Starting with the study of Man-

\footnotetext{
The views expressed in this work are those of the authors and do not necessarily reflect those of the Borsa Istanbul or its members.

* Address: Borsa Istanbul, Research Department, Resitpasa Mahallesi, Tuncay Artun Caddesi, Emirgan, Istanbul 34467, Turkey. Tel.: +90 2122982739 ; fax: +90 2122982189.

E-mail addresses: ahmet.sensoy@imkb.gov.tr, ahmets@fen.bilkent. edu.tr, ahmet.sensoy@borsaistanbul.com
}

delbrot [2], many others have supported the existence of long memory in asset returns (see [3] and the references therein). The presence of such memory brings out several problems in modern finance: (i) the investors' preferred investment horizon becomes a factor in the investment risk [4], (ii) methods used to price financial derivatives may not be useful anymore, (iii) usual tests based on Capital Asset Pricing Model cannot be applied to series that have long term memory [5,6].

This study focuses on the efficiency of the markets in FEAS. Although there is a vast amount of literature on efficiency of developed markets [7-16], less is known for the emerging ones [5,6,17-20]. ${ }^{1}$ In particular, there is not a market efficiency analysis on FEAS in the literature. FEAS

\footnotetext{
${ }^{1}$ In all these studies, several methodologies are used to detect or measure efficiency of financial time series. For example, Carbone et al. [15] calculates Hurst exponent by the scaling technique of detrended moving average to analyze long-range dependence, on the other hand Cajueiro and Tabak $[5,10,16]$ use the classical R/S analysis, local Whittle methodology and multi-fractal detrended fluctuation analysis respectively to estimate the same exponent.
} 
was established with its headquarters in Istanbul on 1995 with 12 founding members, and it has grown to 34 members and 15 affiliate members in 28 countries as a non-profit organization. The federation states its mission as to help create fair, efficient and transparent market environments among its members and in their operating regions. It also aims to minimize barriers to trade through the adoption of best practices for listing, trading and settlement besides promoting linkages among members for cross-border trading. Upon FEAS' rising importance in the world financial system,
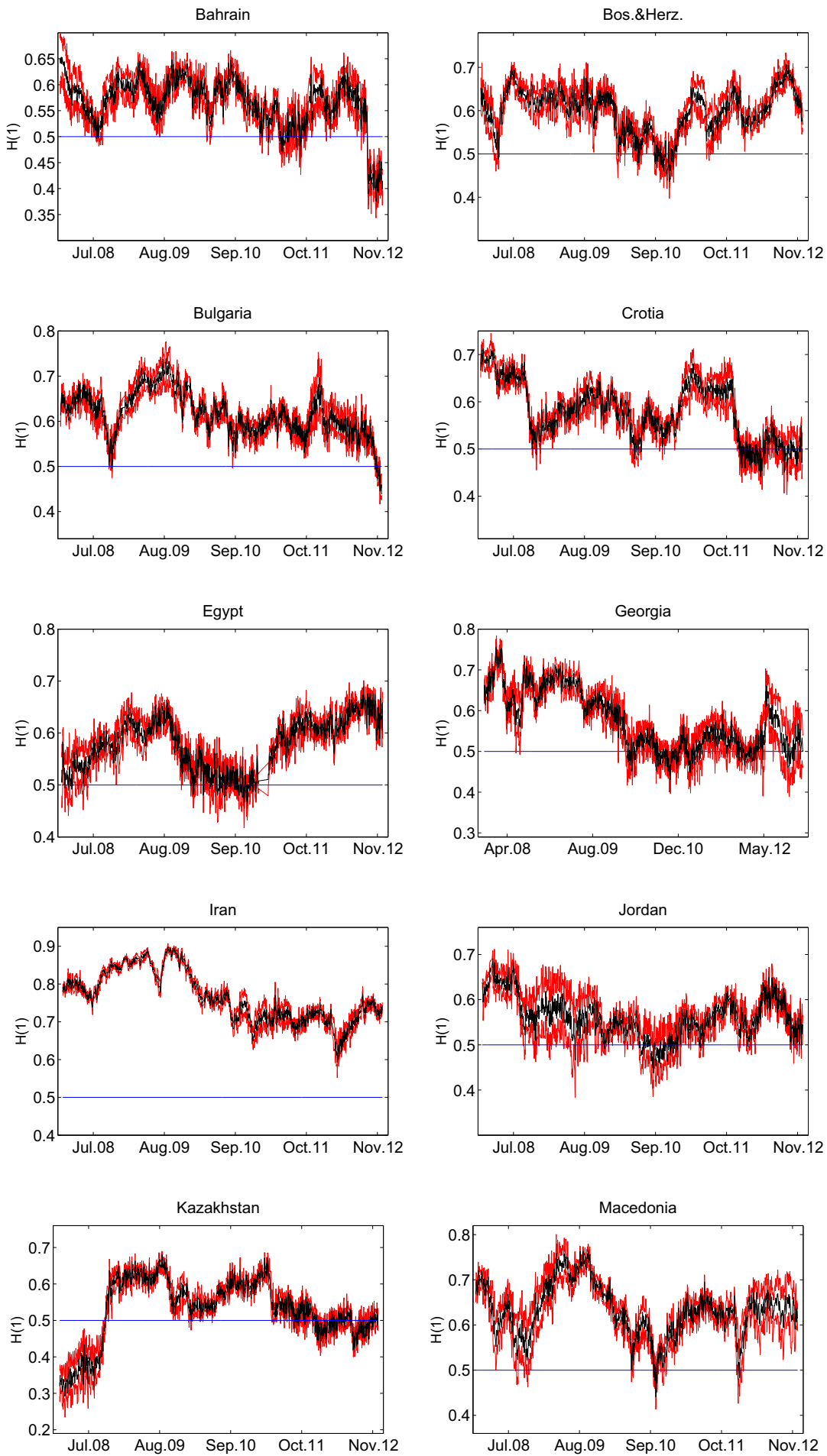

Fig. 1. Time-varying Hurst exponents $H(1)$ of FEAS members. 
in June 2009, Dow Jones Indexes launched a series of benchmark indexes based on the performance of some FEAS equity markets.

We use the Hurst exponent to measure long range dependence in FEAS members. It uses a rolling sample
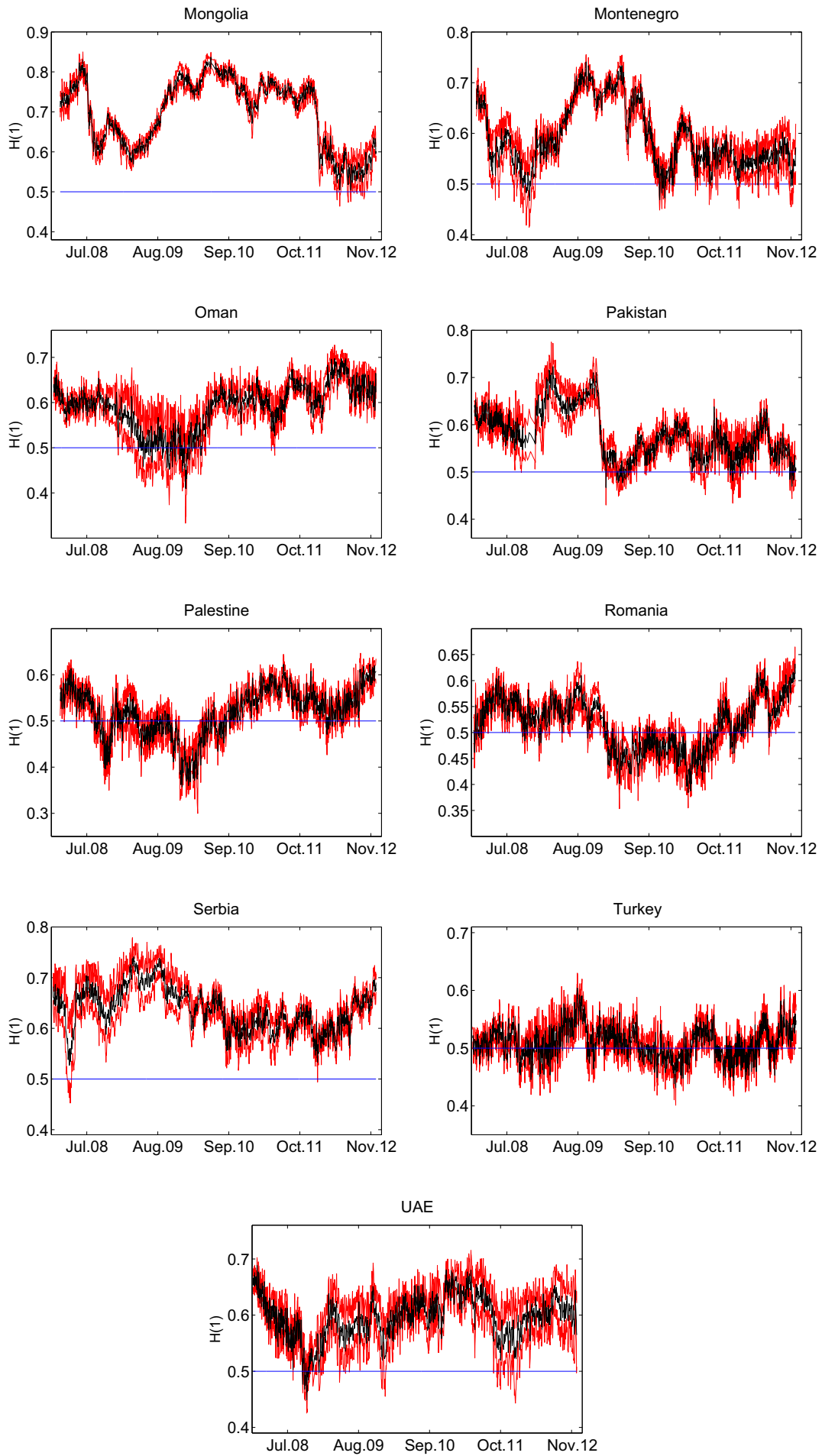

Fig. 1. (continued) 
data and simplicity. Furthermore, since it does not deal with max and min functions, it is less sensitive to outliers than the popular R/S statistics [23].

The rest of the paper is organized as follows: Section 2 explains the methodology for analysis of long range dependence and Section 3 describes the data. Section 4 presents the results and finally Section 5 offers a brief conclusion.

\section{Methodology}

Several methods have been proposed to analyze the long range dependence phenomenon. ${ }^{2}$ In this study, we are interested in the degree of long range dependence of a given stochastic process $S(t)$ with $t=(1,2, \ldots, \Delta t)$ defined over a time window $\Delta t$ with unitary time steps [7] and we use GHE as a measure of long range dependence. ${ }^{3}$ It is a generalization of the approach proposed in [21] and it may be evaluated using the qth-order moments of the distribution of increments, which is a good characterization of the statistical evolution of $S(t)[7,8]$,

$K_{q}(\tau)=\frac{\left\langle|S(t+\tau)-S(t)|^{q}\right\rangle}{\left\langle|S(t)|^{q}\right\rangle}$

where $\tau$ can vary between 1 and $\tau_{\max }$ and $\langle\ldots\rangle$ denotes the sample average over the time window. ${ }^{4}$ GHE is then defined for each time scale $\tau$ and each parameter $q$ as

$K_{q}(\tau) \propto \tau^{q H(q)}$

The GHE is computed from an average over a set of values corresponding to different values of $\tau_{\max }$ in Eq. (1) $[25,26] .^{5}$ For any value of $q, H(q)=0.5$ means that $S(t)$ does not exhibit long range dependence, while $H(q)>0.5$ and $H(q)<0.5$ implies that $S(t)$ is persistent and anti-persistent respectively.

\section{Data}

We consider trading day closing values $P(t)$ of 19 FEAS members i.e. Bahrain (Bahrain All Share Index), Bosnia and Herzegovina (SASE 10), Bulgaria (SOFIX), Croatia (CROBEX), Egypt (EGX 30), Georgia (GSX), Iran (TEPIX), Jordan (ASE General Index), Kazakhstan (KASE), Macedonia (MIB 10), Mongolia (MSE TOP 20), Montenegro (MONEX 20), Oman (MSM 30), Pakistan (Karachi 100), Palestine (Al Quds), Romania (BET), Serbia (BELEX 15), Turkey (BIST100) and United Arab Emirates (ADX General Index). ${ }^{6}$ For

\footnotetext{
${ }^{2}$ See [24] for a survey of these methods.

${ }^{3}$ GHE was introduced in [22] and recently used by Di Matteo et al. [25] to study the degree of development of several financial markets.

${ }^{4}$ Note that for $q=1$, Eq. (1) describes the scaling behavior of the absolute increments and it is expected to be closely related to the original Hurst exponent. For $q=2, K_{q}(\tau)$ is proportional to the autocorrelation function $C(t, \tau)=\langle S(t+\tau) S(t)\rangle$. We will focus on the case of $q=1$.

5 Processes with a scaling behavior of (2) may be divided into two classes: (i) unifractal processes that $H(q)$ is independent of $q$ i.e. $H(q)=H$ or (ii) multifractal processes that $H(q)$ is not constant and each moment scales with a different exponent. Previous researches $[5,6,25,27]$ show that financial time series exhibit multifractal scaling behavior. If multifractality exists in stock returns then models such as in the work of Calvet and Fisher [28] may be used for forecasting, which are competitors to ARCH and GARCH models [23].

${ }^{6}$ This list covers almost $100 \%$ market capitalization of the federation.
}

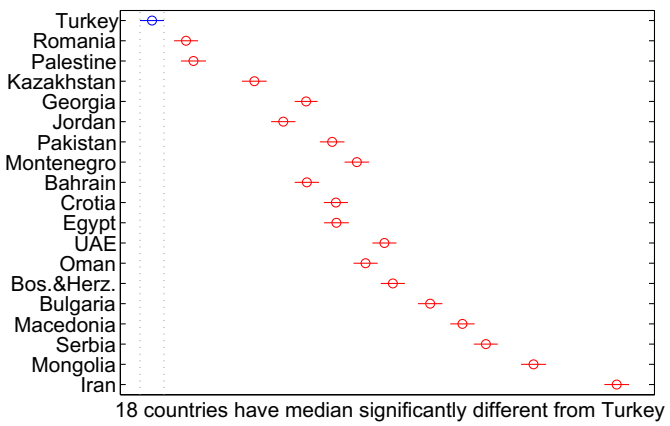

Fig. 2. Multiple median comparison of $H(1)$ samplings among FEAS markets (at $1 \%$ significance level).

comparison purposes, all stock market indexes were started and ended at 02/01/2007 and 26/12/2012 respectively. From daily closing values, daily $\log$-prices $S(t)=\ln P(t)$ are obtained. We use a rolling window of $\Delta t=252$ observations $^{7}$ that shift one point at a time to calculate GHE. Note that for a given time-window $[t-\Delta t+1, t]$, the relation (2) leads to the following

$\ln K_{q}(t, \tau)=q H(q) \ln \tau+C$

From log-prices we compute GHE following the steps in [7,25,26]: we estimate $H(q)$ as an average of several linear fits of Eq. (3) with $\tau \in\left[1, \tau_{\max }\right]$ and $\tau_{\max }$ varying between 5 and 19 days. We take the standard deviation of the $H(q)$ over this range of $\tau_{\max }$ as proxy for standard error of the estimates.

\section{Results}

In Fig. 1, the time-varying GHE for $q=1$ are presented. Fig. 1 also contains the standard errors of GHE (red curves $^{8}$ ) and the line $H=0.5$ (blue line) to compare the results with a theoretical efficient market.

For almost all markets, $H(1)$ displays mixed behavior in the considered time period (varying widely for some of the countries) but in general $H(1)>0.5$ i.e. FEAS members exhibit persistent long range memory. In general, there is a tendency towards efficiency in eastern European members whereas most of the markets in the middle east displays divergence from efficiency especially after the beginning of the Arabian Spring. Turkey varies from others by its stable $H(1)$ that takes values around 0.5 which is a characteristic of a developed financial market [25]. Table 1 presents the descriptive statistic for the time-varying $H(1)$ for all FEAS members.

In order to check whether the time-varying Hurst exponents are due to noise, we performed several normality tests (see Table 1 ) and the results strongly suggest that these parameters are not normally distributed..$^{9}$ Therefore,

\footnotetext{
${ }^{7}$ Window length is chosen to be large enough that it provides satisfactory statistical significance and small enough that it retains sensitivity to changes occurring over time.

${ }^{8}$ For interpretation of the references to color in this figure legend, the reader is referred to the web version of this article.

${ }^{9}$ Indeed, in most of the cases bi-modality is observed giving a clue of "two" Hurst exponents.
} 
Table 1

Descriptive statistics of the time-varying $H(1)$.

\begin{tabular}{|c|c|c|c|c|c|c|c|c|c|c|}
\hline & Bahrain & Bos. \& Herz. & Bulgaria & Croatia & Egypt & Georgia & Iran & Jordan & Kazakhstan & Macedonia \\
\hline Mean & 0.566 & 0.599 & 0.615 & 0.579 & 0.578 & 0.569 & 0.766 & 0.560 & 0.532 & 0.632 \\
\hline Median & 0.575 & 0.608 & 0.613 & 0.580 & 0.587 & 0.550 & 0.755 & 0.557 & 0.543 & 0.632 \\
\hline Max & 0.653 & 0.706 & 0.739 & 0.713 & 0.689 & 0.756 & 0.899 & 0.691 & 0.680 & 0.767 \\
\hline Min & 0.376 & 0.436 & 0.439 & 0.442 & 0.455 & 0.431 & 0.593 & 0.438 & 0.292 & 0.441 \\
\hline SD & 0.047 & 0.050 & 0.048 & 0.060 & 0.050 & 0.072 & 0.067 & 0.044 & 0.084 & 0.057 \\
\hline Kurtosis & -1.268 & -0.600 & -0.144 & 0.007 & -0.235 & 0.439 & 0.187 & 0.229 & -0.781 & -0.071 \\
\hline Skewness & 5.262 & 2.990 & 3.414 & 2.085 & 1.997 & 2.071 & 2.082 & 2.832 & 3.024 & 2.945 \\
\hline J-B test $p$-value & 0.000 & 0.000 & 0.004 & 0.000 & 0.000 & 0.000 & 0.000 & 0.005 & 0.000 & 0.500 \\
\hline Lilliefors test $p$-value & 0.000 & 0.000 & 0.000 & 0.000 & 0.000 & 0.000 & 0.000 & 0.000 & 0.000 & 0.000 \\
\hline \multirow[t]{2}{*}{ Shapiro-Wilk test $p$-value } & 0.000 & 0.000 & 0.000 & 0.000 & 0.000 & 0.000 & 0.000 & 0.000 & 0.000 & 0.000 \\
\hline & Mongolia & Montenegro & Oman & Pakistan & Palestine & Romania & Serbia & Turkey & UAE & \\
\hline Mean & 0.695 & 0.592 & 0.588 & 0.579 & 0.519 & 0.517 & 0.638 & 0.510 & 0.596 & \\
\hline Median & 0.723 & 0.574 & 0.598 & 0.572 & 0.525 & 0.523 & 0.637 & 0.509 & 0.597 & \\
\hline Max & 0.837 & 0.741 & 0.698 & 0.723 & 0.623 & 0.632 & 0.741 & 0.604 & 0.689 & \\
\hline Min & 0.504 & 0.467 & 0.409 & 0.467 & 0.357 & 0.384 & 0.527 & 0.432 & 0.449 & \\
\hline SD & 0.084 & 0.063 & 0.052 & 0.052 & 0.052 & 0.049 & 0.042 & 0.027 & 0.037 & \\
\hline Skewness & -0.398 & 0.540 & -0.566 & 0.405 & -0.586 & -0.199 & 0.078 & 0.179 & -0.388 & \\
\hline Kurtosis & 1.840 & 2.210 & 2.944 & 2.432 & 3.088 & 2.213 & 2.427 & 2.912 & 3.331 & \\
\hline $\mathrm{J}$-B test $p$-value & 0.000 & 0.000 & 0.000 & 0.000 & 0.000 & 0.000 & 0.000 & 0.030 & 0.000 & \\
\hline Lilliefors test $p$-value & 0.000 & 0.000 & 0.000 & 0.000 & 0.000 & 0.000 & 0.005 & 0.011 & 0.000 & \\
\hline Shapiro-Wilk test $p$-value & 0.000 & 0.000 & 0.000 & 0.000 & 0.000 & 0.000 & 0.000 & 0.030 & 0.000 & \\
\hline
\end{tabular}

we can employ usual non-parametric tests to compare the medians of different markets' Hurst exponent time series. Table 2 gives a ranking of medians and means of these markets based on the distance between 0.5 and $H(1)$ : Turkey is the least inefficient market in the federation followed by Romania while the most inefficient markets are Iran, Mongolia, Serbia and Macedonia, and the ranking in the middle is ambiguous. ${ }^{10}$

\subsection{Influence of liquidity on long-range dependence}

In this section, we seek financial reasoning for our efficiency ranking. Three important market liquidity indicators namely; trade volume, turnover and market capitalization are considered. We proceed as follows: Notice that each index contains a specific number of stocks (that differs from one index to another) thus, for comparison purposes we first calculate daily average trade volume, turnover (USD) and market capitalization (USD) per stock for each index. Next, rankings of the markets are constructed for each of these three categories. Finally, we compare these rankings with our previously found efficiency ranking. ${ }^{11}$ The results are given in Fig. 3 .

\footnotetext{
${ }^{10}$ For these rankings to be meaningful, medians must be significantly different from each other. The Kruskal-Wallis test evaluates the hypothesis that all samples come from populations that have the same median, against the alternative that the medians are not all the same. In our case, we need to perform a test to determine which pairs are significantly different, and which are not with a multiple comparison approach. The results are given in Fig. 2 and it shows that most of the pairwise medians are significantly different.

11 Trade volume, turnover and market cap data for Iran, Georgia, Serbia and Palestine is not available so we remove these markets in this part of our analysis. Similarly, the market cap and turnover data is not available for Bosnia and Herzegovina so this member is omitted in the relevant analysis.
}

Table 2

Efficiency ranking of FEAS members based on the distance between 0.5 and median/mean of $H(1)$.

\begin{tabular}{llll}
\hline Market & $\begin{array}{l}\text { Median (distance } \\
\text { to 0.5) }\end{array}$ & Market & $\begin{array}{l}\text { Mean (distance } \\
\text { to 0.5) }\end{array}$ \\
\hline Turkey & $0.5093(0.0093)$ & Turkey & $0.5096(0.0096)$ \\
Romania & $0.5233(0.0233)$ & Romania & $0.5171(0.0171)$ \\
Palestine & $0.5245(0.0245)$ & Palestine & $0.5191(0.0191)$ \\
Kazakhstan & $0.5430(0.0430)$ & Kazakhstan & $0.5322(0.0322)$ \\
Georgia & $0.5500(0.0500)$ & Jordan & $0.5600(0.0600)$ \\
Jordan & $0.5572(0.0572)$ & Bahrain & $0.5657(0.0657)$ \\
Pakistan & $0.5720(0.0720)$ & Georgia & $0.5694(0.0694)$ \\
Montenegro & $0.5744(0.0744)$ & Egypt & $0.5782(0.0782)$ \\
Bahrain & $0.5746(0.0746)$ & Croatia & $0.5789(0.0789)$ \\
Croatia & $0.5799(0.0799)$ & Pakistan & $0.5789(0.0789)$ \\
Egypt & $0.5871(0.0871)$ & Oman & $0.5884(0.0884)$ \\
UAE & $0.5970(0.0970)$ & Montenegro & $0.5915(0.0915)$ \\
Oman & $0.5976(0.0976)$ & UAE & $0.5956(0.0956)$ \\
Bos.\& Herz. & $0.6082(0.1082)$ & Bos.\& Herz. & $0.5988(0.0988)$ \\
Bulgaria & $0.6126(0.1126)$ & Bulgaria & $0.6151(0.1151)$ \\
Macedonia & $0.6317(0.1317)$ & Macedonia & $0.6316(0.1316)$ \\
Serbia & $0.6374(0.1374)$ & Serbia & $0.6379(0.1379)$ \\
Mongolia & $0.7227(0.2227)$ & Mongolia & $0.6948(0.1948)$ \\
Iran & $0.7550(0.2550)$ & Iran & $0.7656(0.2656)$ \\
\hline
\end{tabular}

The scatter diagram in Fig. 3 and the simple regressions obtained from ordinary least-squares estimation ${ }^{12}$ clearly state that there exists a positive strong relationship between efficiency and liquidity. For example, Turkey and Romania, highest ranked members in efficiency, are also ranked highest in terms of daily average liquidity proxies per stock. Our findings are in parallel with the results of Cajueiro and Tabak [29-31]. Authors reveal that liquidity plays a significant role in explaining market efficiency in Brazilian stock market [31] and major stock markets of Asia [29,30]. Combining these facts suggests that for an improvement in a market's

\footnotetext{
12 See the equations in Fig. 3.
} 

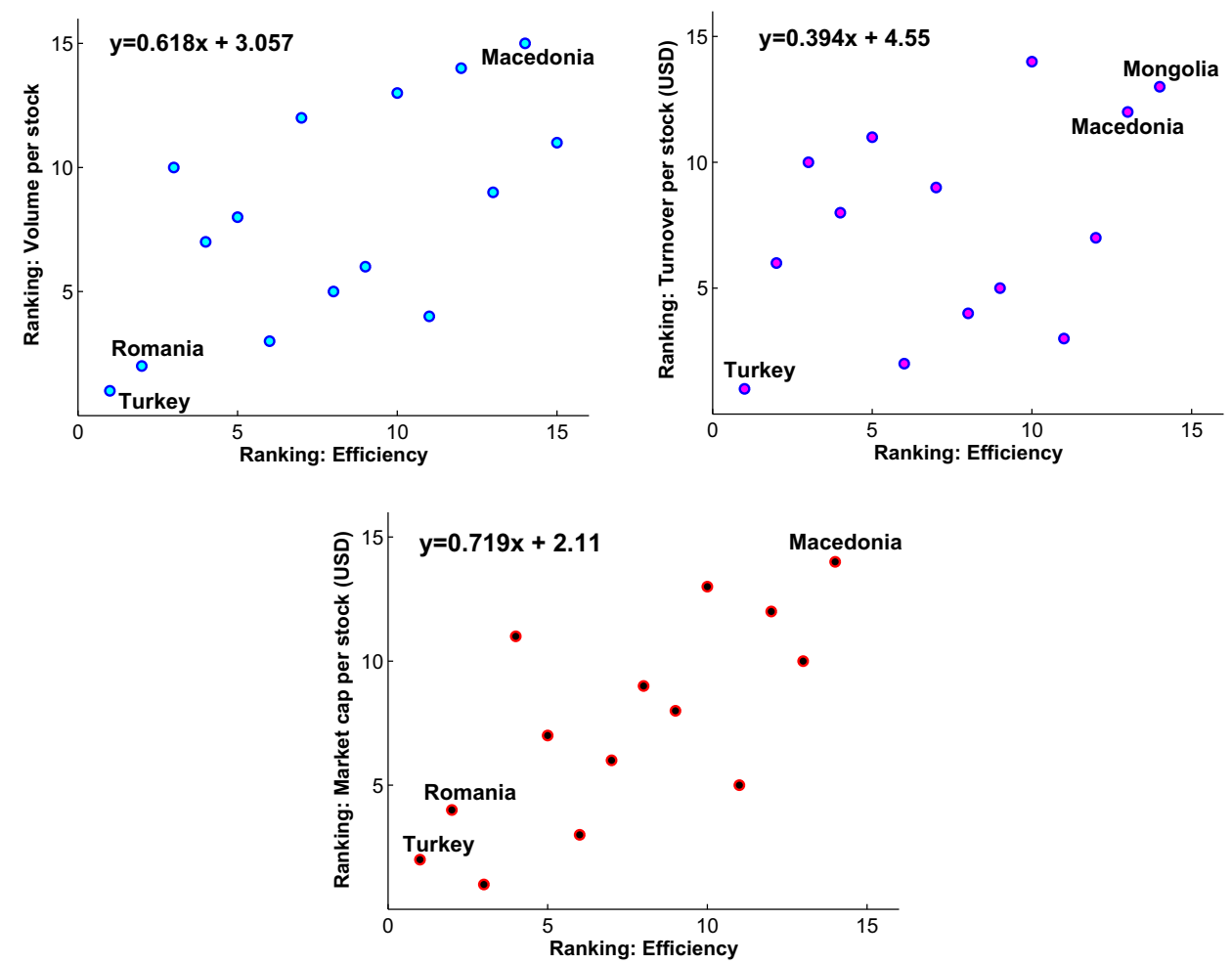

Fig. 3. The relationship between main liquidity indicators and market efficiency.

efficiency, policy makers should focus on increasing the liquidity.

\section{Conclusion}

Market efficiency is not easy to test or measure empirically, however, it has vital implications: In an efficient market, there is no room for fooling investors. They can pursue a buy-and-hold strategy since this will lead to the same returns on average but the net profit will be higher due to fewer brokerage commissions. Considering the creditors, an efficient market can help determining whether a company is in the solvency condition or not and it assists them to decide the most potential company to join as the debenture holders due to the available information provided.

To observe the time-varying market efficiency in the Euro-Asian region, the concept of generalized Hurst exponents has been applied to FEAS members' daily data between 2007 and 2012 by a rolling window approach. The results show that these markets display persistent long range memory in general. Through this time period, in general, eastern European markets evolves to a less inefficient state while middle eastern members diverge from efficiency. Moreover, divergence is observed around the beginning of Arabian Spring, which possibly has a partial responsibility in this artifact.

The markets have been ranked according to their efficiency and the least inefficient market is found to be Turkey, succeeded by Romania, while the most inefficient markets are Iran, Mongolia, Serbia and Macedonia. Furthermore, by its stable Hurst exponent around 0.5, Turkey differs from others and shows characteristics of a developed market throughout the considered time period.

For FEAS member, strong positive relationship between efficiency and market liquidity is revealed. In the light of this fact, the possible suggestions to improve market efficiency are the followings: Most of the members in FEAS do not have derivative markets. Literature shows that launch of derivative assets, in general, increases the underlying market's liquidity $[32,33]$, thus introducing a derivative market could increase efficiency. Similarly, recent studies [34,35] reveal that making short selling difficult has an adverse effect on liquidity. In that case, lowering short sale margin requirements or removing of the up-tick rule would possibly have a positive effect on efficiency. We hope our findings would be useful for investors, portfolio managers and policy makers.

\section{Acknowledgments}

We thank to anonymous referees for helpful comments and suggestions that significantly improved this paper.

\section{References}

[1] Fama E. Efficient capital markets: a review of theory and empirical work. J Financ 1970;25:383-417.

[2] Mandelbrot B. When can price be arbitraged efficiently? A limit to the validity of the random-walk and martingale models. Rev Econ Stat 1971;53:225-36. 
[3] Plerou V, Gopikrishnan P, Rosenow B, Amaral LAN, Stanley HE. Econophysics: financial time series from a statistical physics point of view. Physica A 2000;279:443-56.

[4] Mandelbrot B. Fractals and scaling in finance: discontinuity, concentration, risk. New York: Springer; 1997.

[5] Cajueiro DO, Tabak BM. The Hurst exponent over time: testing the assertion that emerging markets are becoming more efficient. Physica A 2004;336:521-37.

[6] Cajueiro DO, Tabak BM. Testing for time-varying long-range dependence in volatility for emerging markets. Physica A 2005; 346:577-88.

[7] Morales R, Di Matteo T, Gramatica R, Aste T. Dynamical generalized Hurst exponent as a tool to monitor unstable periods in financial time series. Physica A 2012;391:3180-9.

[8] Cajueiro DO, Tabak BM. Fluctuation dynamics in us interest rates and the role of monetary policy. Financ Res Lett 2010;7:163-9.

[9] Cajueiro DO, Tabak BM. Long-range dependence and market structure. Chaos Solitons Fract 2007;31:995-1000.

[10] Cajueiro DO, Tabak BM. Time-varying long-range dependence in US interest rates. Chaos Solitons Fract 2007;34:360-7.

[11] Batten JA, Ellis CA, Fethertson TA. Sample period selection and longterm dependence: new evidence from the Dow Jones index. Chaos Solitons Fract 2008;36:1126-40.

[12] Souza SR, Tabak BM, Cajueiro DO. Long memory testing for fed funds futures' contracts. Chaos Solitons Fract 2008;37:180-6.

[13] Cajueiro DO, Tabak BM. Testing for long-range dependence in world stock markets. Chaos Solitons Fract 2008;37:918-27.

[14] Frezza M. Modeling the time-changing dependence in stock markets. Chaos Solitons Fract 2012;45:1510-20.

[15] Carbone A, Castelli G, Stanley HE. Time dependent Hurst exponent in financial time series. Physica A 2004;344:267-71.

[16] Cajueiro DO, Tabak BM. Multifractality and herding behavior in the Japanese stock market. Chaos Solitons Fract 2009;40:497-504.

[17] Cajueiro DO, Tabak BM. Ranking efficiency for emerging markets. Chaos Solitons Fract 2004;22:349-52.

[18] Cajueiro DO, Tabak BM. Ranking efficiency for emerging markets II. Chaos Solitons Fract 2005;23:671-5.

[19] Lima EJA, Tabak BM. Testing for inefficiency in emerging markets exchange rates. Chaos Solitons Fract 2007;33:617-22.
[20] Cajueiro DO, Tabak BM. Testing for long-range dependence in the Brazilian term structure of interest rates. Chaos Solitons Fract 2009;40:1559-73.

[21] Hurst E. Long-term storage capacity of reservoirs. Trans Am Soc Civ Eng 1951;116:770-808.

[22] Barabasi AL, Vicsek T. Multifractality of self-affine fractals. Phys Rev A $1991 ; 44: 2730-3$

[23] Cajueiro DO, Gogas P, Tabak BM. Does financial market liberalization increase the degree of market efficiency? The case of the Athens stock exchange. Int Rev Financ Anal 2009;18:50-7.

[24] Taqqu MS, Teverovsky V, Willinger W. Estimators for long-range dependence: an empirical study. Fractals 1995;3:785-98.

[25] Di Matteo T, Aste T, Dacorogna MM. Long-term memories of developed and emerging markets: using the scaling analysis to characterize their stage of development. J Bank Finance 2005;29: 827-51.

[26] Di Matteo T, Aste T, Dacarogna MM. Scaling behaviors in differently developed markets. Physica A 2003;324:183-8.

[27] Di Matteo T. Multi-scaling in finance. Quant Finance 2007;7:21-36.

[28] Calvet L, Fisher A. Multifractality in asset returns: theory and evidence. Rev Econ Stat 2001;84:381-406.

[29] Cajueiro DO, Tabak BM. Evidence of long range dependence in Asian equity markets: the role of liquidity and market restrictions. Physica A 2004;342:656-64.

[30] Cajueiro DO, Tabak BM. The long-range dependence phenomena in asset returns: the Chinese case. Appl Econ Lett 2006;13:131-3.

[31] Cajueiro DO, Tabak BM. Possible causes of long-range dependence in the Brazilian stock market. Physica A 2005;345:635-45.

[32] Faff R, Hillier D. Complete markets, informed trading and equity option introductions. J Bank Finance 2005;29:1359-84.

[33] Lee CI, Tong HC. Stock futures: the effects of their trading on the underlying stocks in Australia. J Multinat Financ Manage 1998;8: 285-301.

[34] Marsh I, Payne R. Banning short sales and market quality: the UK's experience. J Bank Finance 2012;36:1975-86.

[35] Beber A, Pagano M. Short selling bans around the world: evidence from the 2007-09 crisis. J Financ 2013;68:343-81. 